\title{
A comparative study of satellite and ground-based phenology
}

\section{Journal Article}

Author(s):

Studer, S.; Stöckli, R.; Appenzeller, C.; Vidale, Pier Luigi

Publication date:

2007

Permanent link:

https://doi.org/10.3929/ethz-b-000005530

Rights / license:

In Copyright - Non-Commercial Use Permitted

Originally published in:

International Journal of Biometeorology 51(5), https://doi.org/10.1007/s00484-006-0080-5 


\title{
A comparative study of satellite and ground-based phenology
}

\author{
S. Studer • R. Stöckli • C. Appenzeller • P. L. Vidale
}

Received: 23 June 2006 /Revised: 11 December 2006 / Accepted: 12 December 2006 / Published online: 18 January 2007

(C) ISB 2007

\begin{abstract}
Long time series of ground-based plant phenology, as well as more than two decades of satellite-derived phenological metrics, are currently available to assess the impacts of climate variability and trends on terrestrial vegetation. Traditional plant phenology provides very accurate information on individual plant species, but with limited spatial coverage. Satellite phenology allows monitoring of terrestrial vegetation on a global scale and provides an integrative view at the landscape level. Linking the strengths of both methodologies has high potential value for climate impact studies. We compared a multispecies index from ground-observed spring phases with two types (maximum slope and threshold approach) of satellitederived start-of-season (SOS) metrics. We focus on Switzerland from 1982 to 2001 and show that temporal and spatial variability of the multispecies index correspond well with the satellite-derived metrics. All phenological metrics correlate with temperature anomalies as expected. The
\end{abstract}

S. Studer $\cdot$ C. Appenzeller

Federal Office of Meteorology and Climatology MeteoSwiss,

Krähbühlstr. 58,

8044 Zurich, Switzerland

R. Stöckli $(\square)$

Institute for Atmospheric and Climate Science, ETH Zurich,

8092 Zurich, Switzerland

e-mail: stockli@env.ethz.ch

P. L. Vidale

NCAS, Department of Meteorology,

University of Reading,

Reading, UK

R. Stöckli

Department of Atmospheric Science, Colorado State University, Fort Collins, CO 80523, USA slope approach proved to deviate strongly from the temporal development of the ground observations as well as from the threshold-defined SOS satellite measure. The slope spring indicator is considered to indicate a different stage in vegetation development and is therefore less suited as a SOS parameter for comparative studies in relation to ground-observed phenology. Satellite-derived metrics are, however, very susceptible to snow cover, and it is suggested that this snow cover should be better accounted for by the use of newer satellite sensors.

Keywords Satellite phenology - Ground-based phenology · NDVI $\cdot$ Methodological comparison $\cdot$ Climate change

\section{Introduction}

In the context of climate change, knowledge of climatic impacts on ecosystems has become important: recent warming trends in the northern hemisphere clearly show up in phenological time-series with earlier spring and later autumn dates (Menzel 2000; Roetzer et al. 2000; Defila and Clot 2001; Parmesan and Yohe 2003; Root et al. 2003; Studer et al. 2005).

Since vegetation can influence the atmospheric state (Pielke 2001) and the surface climate (Bounoua et al. 2002), plant phenology can have a strong biophysical control in present and future climate model simulations.

Phenological measurements are currently made via two completely different approaches. Ground-observed phenology offers a high temporal resolution and detailed information about individual species, but it has poor spatial coverage (Ricotta and Avena 2000; Schwartz et al. 2002; White et al. 2005). Satellite-derived phenology, as a complementary observation method, offers full spatial 
coverage on a global scale while providing temporal information about radiative characteristics of vegetation. Satellite remote sensing allows scientists to explore phenological events at the landscape scale, while ground observations focus on the phenological performance of specific plants during the vegetation period (Reed et al. 1994; Ricotta and Avena 2000; Schwartz et al. 2002).

Linking ground-based observations with those from space has the great potential to enhance our ability to track the biotic response to climate change (Beaubien and Hall-Beyer 2003). To assess satellite comparability with traditional groundbased phenological observations, comparative studies are required (Chen et al. 2001; Beaubien and Hall-Beyer 2003; Braun and Hense 2004).

\section{Overview of traditional phenology}

In several European countries, plant phenological observation networks are run by the National Weather Services and cover the second half of the twentieth century. But only in the last decade have "phenological perspectives" been rapidly incorporated into the mainstream of science, especially in relation to the needs of global change research (Schwartz 2003). Numerous studies show evidence of a shift in plant development towards an earlier onset of spring in Europe (Menzel 2000; Roetzer et al. 2000; Defila and Clot 2001; Menzel et al. 2001; Ahas et al. 2002; Studer et al. 2005) and in North America (Beaubien and Freeland 2000; Schwartz and Reiter 2000; Cayan et al. 2001). The trends towards an earlier spring onset, for several species and phases, range from 1.4 to 3.8 days/decade over the last 50 years.

For individual species, this change in phenological development could be clearly linked to changes in winter and spring air temperature (Heikinheimo and Lappalainen 1997; Ahas et al. 2000; Sparks et al. 2000; Chmielewski and Rötzer 2001; Defila and Clot 2001; Menzel 2003). Since there is considerable variability among different plant species and phases, a general assessment of plant development responses in recent decades is difficult to generate from these studies. A more general multispecies index, as developed by Studer et al. (2005), overcomes this problem and supports the results on the individual species scale.

Developments in satellite phenology

Since the 1980s, multi-spectral satellite observations from the National Oceanic and Atmospheric Administration's (NOAA) Polar Orbiting Environmental Satellites have provided daily global coverage datasets of visible and near-infrared surface reflectances. From these, the Normalized Difference Vegetation Index (NDVI) can be derived (Justice et al. 1985; Tucker and Sellers 1986; Reed et al.
1994). The NDVI exploits the spectral properties of green plant leaves and is an estimate of the radiation used within the photosynthesis process occurring in leaves. The data, however, are affected by various atmospheric disturbances (aerosol, ozone and water vapour absorptions), cloud cover, solar illumination effects, instrument degradation, insufficient calibration and satellite orbit drifts (Holben 1986), which can be corrected (Cihlar et al. 1994; Los et al. 2000).

Large-scale variations in NDVI have been successfully related to interannual climatic variations: temperate coastal NDVI is influenced by temperature variations while tropical, subtropical and continental NDVI is best explained by precipitation variations (Los et al. 2001). Temperature anomalies and the North Atlantic Oscillation correlate well with the early or late growing seasons derived from European NDVI (Stöckli and Vidale 2004). Global NDVI data can also be used to verify trends in ground-based vegetation observations. Myneni et al. (1997) investigated the 1981-1991 Advanced Very High Resolution Radiometer (AVHRR) NDVI for the northern hemisphere and detected an advance in the active growing season of $8 \pm$ 3 days and a delay in the declining phase of $4 \pm 2$ days over this decade. Zhou et al. (2001) looked at the northern hemisphere vegetation activity derived from AVHRR NDVI and land surface temperature records between 1981 and 1998 and found an increase in mean NDVI for Eurasia and north America.

The aim of the current study is to provide a methodology which allows an analysis of variability, trends and spatial patterns in both ground- and space-observed phenological datasets. We use different algorithms to calculate the onset of spring, based on the European Fourier-Adjusted and Interpolated (EFAI) NDVI dataset (Stöckli and Vidale 2004) and compare these satellite-derived phenological metrics to the multispecies spring index based on traditional ground observations (Studer et al. 2005). Regarding the integrative nature of satellite-derived phenological metrics, the multispecies spring index is assumed to be a good parameter for a comparison between the two observational datasets. The next sections provide an overview of the applied methodology and present the phenological patterns for satellite and ground observations, investigated for Switzerland for the years 1982-2001.

\section{Materials and methods}

\section{Ground dataset}

The source of the observed phenology data was the Swiss phenological network consisting of a total of 69 observation stations. For the comparison with the satellite-derived phenology, the multispecies dataset for the years 1965- 
2002 and the methods developed by Studer et al. (2005) were used. The phenological dataset consisted of a combination of 15 spring phases representing all types of spring development stages (e.g. bud burst, beginning of flowering, full flowering) from different herb and tree species, covering the period from March to July. The phases were combined into one large multispecies dataset. The observation stations covered an altitudinal range from 200 to $1,800 \mathrm{~m}$ asl. To correct for the slightly uneven geographical distribution of the observation stations, all datasets were weighted by the area represented by the stations within a $50 \mathrm{~km}^{2}$ grid cell. However, the same processed dataset as for the above mentioned study was used (standardised anomalies), but only the years 19822001 were included in the analyses. The same is true for the accumulated growing degree days (GDD) temperature data, consisting of interpolated homogenised station data from 12 meteorological stations in Switzerland. Empirical orthogonal function (EOF) time series of snow depth (accumulated daily new snow depths in the December-February period) were used as published in Scherrer et al. (2004).

\section{Satellite dataset}

The NDVI was calculated from the red (VIS) and nearinfrared (NIR) reflectance measured by satellite radiometers by taking the ratio: NDVI $=(\mathrm{NIR}-\mathrm{VIS}) /(\mathrm{NIR}+\mathrm{VIS})$.
In this study, we used the 1982-2001 EFAI-NDVI dataset (Stöckli and Vidale 2004), which offers continuous and consistent NDVI time-series at a 10-day interval over Europe at a $0.1^{\circ}$ spatial resolution. It has been derived from the NOAA/NASA Pathfinder NDVI dataset (James and Kalluri 1994) by application of second order discrete Fourier series. The original satellite data are corrected for Rayleigh scattering, ozone absorption and instrumental degradation. They are not corrected for the influences of solar zenith angle, water vapour and aerosols.

During the dormant season, the NDVI of deciduous broadleaf vegetation is low $(<0.2)$. It increases rapidly (to values $>0.5$ ) at the beginning of the growing season. NDVI is able to exploit the large-scale state of vegetation, but it cannot be directly compared to bud-burst or flowering dates of individual ground-observed plants. There are, however, a number of methods to derive, e.g., the start of the season (SOS) from NDVI time-series as described in Reed et al. (1994), White et al. (1997), Schwartz et al. (2002), Jonsson and Eklundh (2002) and White et al. (2005), and we have used the following two (Fig. 1):

Threshold method A threshold is defined for each pixel as the midpoint between the minimum and the maximum NDVI value of the whole time-series. In each year, the first crossing of this threshold marks the SOS. Since the NDVI is a measure of photosynthetic activity, this threshold-
Fig. 1 Two methods for deriving SOS (start of season) from the seasonal course of satellite NDVI (Normalized Difference Vegetation Index). Two sample years averaged for Switzerland are shown: 1990 had less snow than 1986. The threshold-derived SOS (dashed vertical lines) captures an earlier spring green-up. This interannual variability is not as visible from the slope-derived SOS (dash-dotted vertical lines)

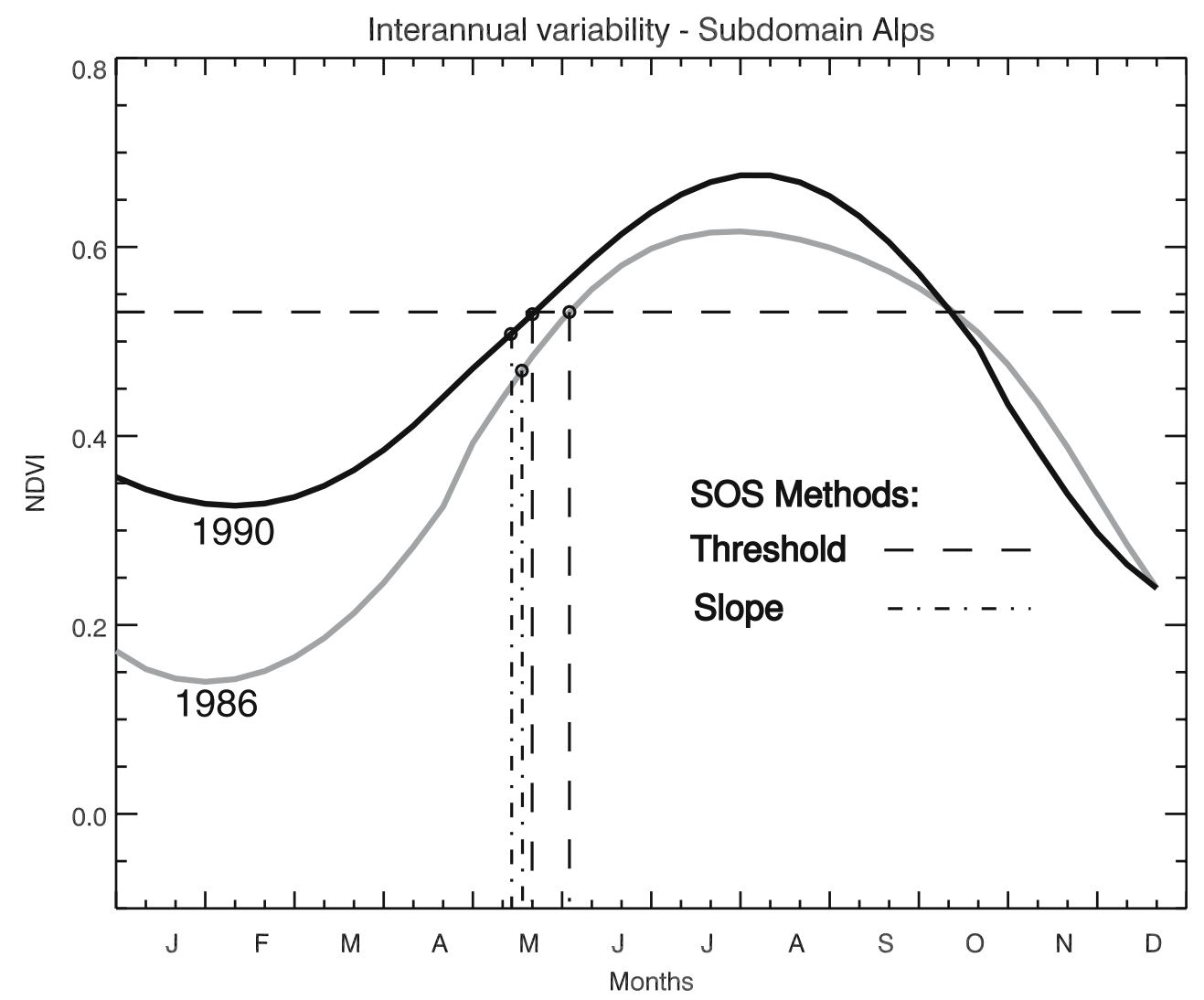


Table 1 Summary statistics of the raw ground observed data and the satellite-derived SOS (start of season) dates: minimum, maximum and mean in days of the year, and mean year-to-year standard deviation over all stations/pixels

\begin{tabular}{lrrrc}
\hline Variable & Minimum & Mean & Maximum & $\begin{array}{c}\text { Standard } \\
\text { deviation }\end{array}$ \\
\hline Ground-observed & 2 & 118.20 & 236 & 10.48 \\
Slope & 25 & 110.45 & 298 & 25.86 \\
Threshold & 36 & 109.10 & 227 & 23.44 \\
Slope lowland & 25 & 85.24 & 298 & 27.27 \\
Threshold lowland & 36 & 80.70 & 227 & 25.50 \\
\hline
\end{tabular}

derived SOS provides a date when the pixel-integrated vegetation has reached a specific phenological state (Fig. 1: dashed lines). This method uses a time-constant threshold, but is sensitive to spatial variations. It may, however, be susceptible to aerosols and satellite orbital drifts which can influence the NDVI.

Slope method This method is based on the first derivate of the NDVI time-series. In each year, its maximum marks the SOS. This method focuses on the rate of increase in vegetation greenness during the transition period between the dormant and the active growing season. NDVI is very sensitive at low leaf areas indices. A fast increase (high slope) in NDVI during the spring period will likely represent the growth of new leaves and mark the SOS (Fig. 1: dash-dotted lines).

Comparison of ground-observed and satellite-derived data

Both satellite-NDVI-based methods (Threshold, Slope) for deriving the SOS were applied to every $0.1^{\circ}$ pixel over Switzerland for the time period 1982-2001. Groundobserved phenological data consisted of the multispecies index during the same time period, but were restricted to lower elevations. Therefore, values above $2,000 \mathrm{~m}$ (mean elevation within a particular pixel) were excluded from the satellite dataset to create a 'lowland' dataset for comparison.

Table 2 Variance (\%) explained by the first four modes of the EOF analyses of the different SOS measures

\begin{tabular}{lcrrrr}
\hline \multicolumn{5}{l}{ Mode } & \multicolumn{3}{l}{ Satellite } \\
\cline { 3 - 6 } & $\begin{array}{l}\text { Ground- } \\
\text { observed }\end{array}$ & Slope & Threshold & $\begin{array}{l}\text { Slope } \\
\text { lowland }\end{array}$ & $\begin{array}{l}\text { Threshold } \\
\text { lowland }\end{array}$ \\
\hline 1 & 46 & 29 & 53 & 48 & 71 \\
2 & 10 & 14 & 10 & 9 & 6 \\
3 & 8 & 8 & 7 & 8 & 4 \\
4 & 5 & 7 & 6 & 6 & 3 \\
Sum & 69 & 58 & 76 & 71 & 84 \\
\hline
\end{tabular}

The ranges of the date values are similar for all methods, but the relative large min-max difference is easier to explain for the observed data where the large range originates from the differences between very early and later phases (Table 1). The standard deviations show that there is
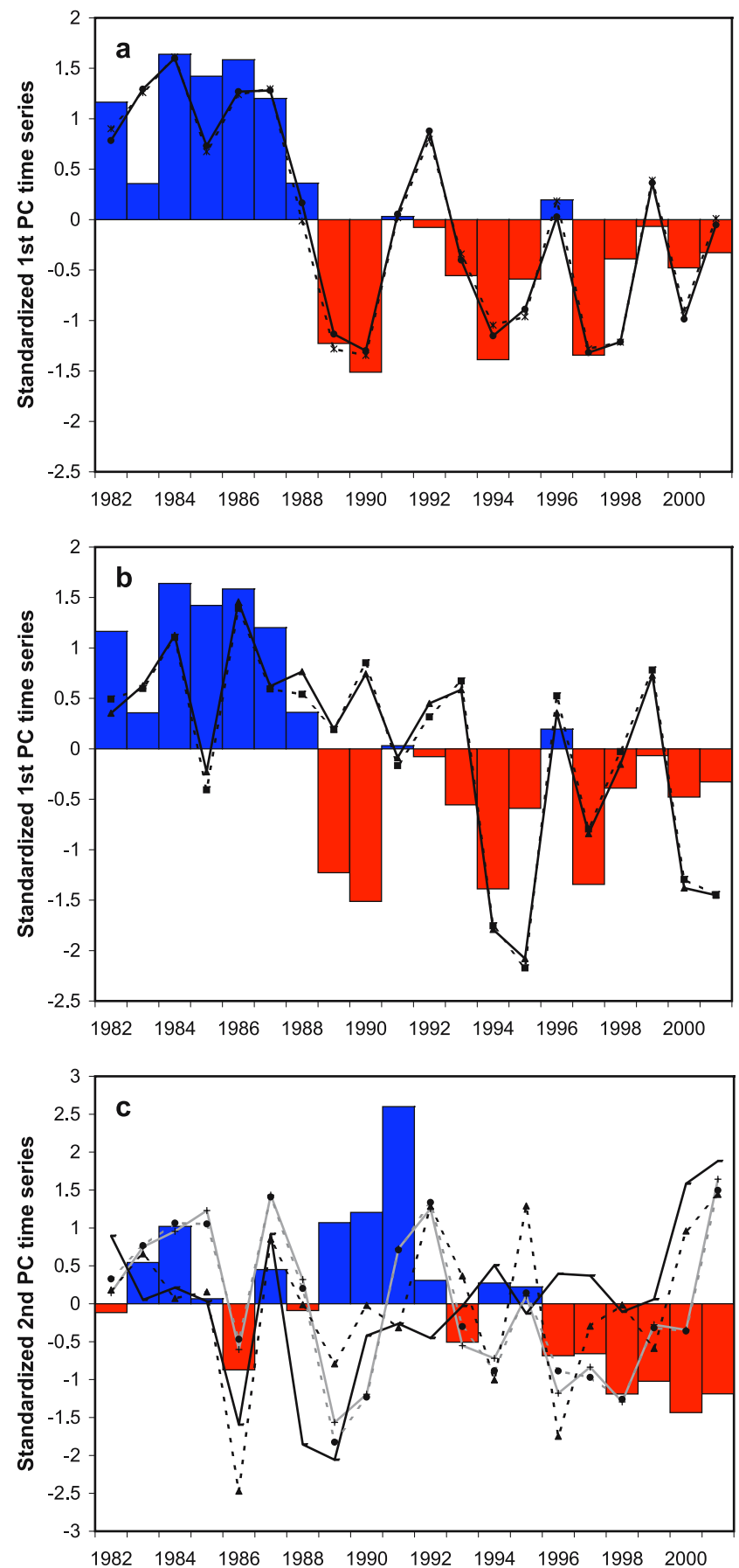

Fig. 2 Time evolution of the leading two principal components of the different phenology parameters. Bars: ground-observed PC; lines: satellite indices PCs full datasets; dotted lines: satellite PCs lowland datasets. a 1st PCs ground-observed and threshold NDVI indices; b 1st PCs ground-observed and slope NDVI indices; c 2nd PCs groundobserved, threshold NDVI (black) and slope (grey) NDVI indices 
clearly more interannual variability at the single pixels than at stations.

\section{Statistical methodology}

The most important patterns of the phenological year-toyear variability were identified by EOF (Bretherton et al. 1992) applied to the normalised multi-species dataset. EOF analyses are widely used in climate research to identify dominant patterns of variability and to reduce the dimensionality of the data (Hannachi et al. 2005). The main purpose of EOF analyses is to reduce the number of variables in large datasets, while retaining as much as possible of the variation present in the principal components. The first few of the resulting variability patterns contain most of the variation present in the original dataset (Jollife 1986). To compare the different datasets the focus is given on the primary variability patterns. The time evolution of the first principal component was used as a robust trend estimate (index) of the phenological development (Studer et al. 2005). As a trend value for the whole country the mean value of the rescaled primary EOF pattern (Hartmann 2002) is given. Statistical analyses were performed using the S-Plus statistical software package (S-PLUS 2000).

\section{Results}

\section{EOF analyses}

The EOF analyses on the different SOS measures showed clear differences in the explained variance among the different phenological indices. The dominant pattern in the observed phenological data explained $69 \%$ of variance on the first four orthogonal functions (EOFs). For the threshold NDVI derived data, the proportion of variance on the first EOF was slightly higher with 53\% explained variance on the first and $76 \%$ on the first four EOFs (Table 2). Using the slope method resulted in a less clear partitioning. The omission of the higher elevated data points in the satellite data led to larger proportions of variance on the first EOF. The threshold lowland, as well as the climate datasets, showed the strongest partitioning with more than $70 \%$ variance concentrated in the first EOF.

Time evolution

All phenological parameters showed a distinct time evolution over the years 1982-2001 on the principal components (PCs) of the first EOF, indicating a tendency towards an earlier onset of spring. But the individual courses of the two satellite-derived data types varied considerably (Fig. 2a,b; Table 3). Omitting the higher elevated data points in the satellite data only led to minor changes in the temporal development. Both types of the threshold NDVI correlated strongly with the observed phenological development, but the slope NDVI less so. A noticeable contrast was obvious in the years 1988-1990. The observed index, as well as the threshold NDVI data, showed a shift towards an earlier onset of spring in these years. In contrast, the shift was not obvious and the trend towards earlier onset of spring was more continuous for the slope data.

The leading PCs of the ground-observed phenology as well as the threshold NDVIs correlated very well with temperature, while for the slope NDVI the correlation was considerably lower (Table 3). Similarly, the slope NDVI showed no relation to snow height, which is known to be a possible influential factor in satellite-derived vegetation indices. None of the measurements showed a close relationship to precipitation.

The trend values found on the first PCs were clearly higher for the NDVI data (5-8.6 days/decade) than for the observed phenology index (3.0 days/decade) (Table 4). In contrast, the relative trends calculated on the standardised PC time series were very consistent.

The second order patterns did not show distinct temporal patterns and the correspondence among the second PCs was generally low (Table 5). The absolute trends in the second PCs were small, and both the absolute and the relative
Table 3 Correlation of the 1 st principal components originating from the different methods

Bold numbers indicate statistically significant correlations $(p<0.05)$

\begin{tabular}{lcccccc}
\hline & $\begin{array}{c}\text { Ground- } \\
\text { observed }\end{array}$ & Slope & Threshold $\begin{array}{l}\text { Slope } \\
\text { lowland }\end{array}$ & $\begin{array}{l}\text { Threshold } \\
\text { lowland }\end{array}$ & Temperature \\
\hline Slope & $\mathbf{0 . 5 2}$ & & & & & \\
Threshold & $\mathbf{0 . 8 9}$ & $\mathbf{0 . 6}$ & & & \\
Slope lowland & $\mathbf{0 . 4 8}$ & $\mathbf{0 . 9 9}$ & $\mathbf{0 . 5 6}$ & & \\
Threshold lowland & $\mathbf{0 . 8 9}$ & $\mathbf{0 . 5 8}$ & $\mathbf{0 . 9 9}$ & $\mathbf{0 . 5 4}$ & & \\
Temperature & $\mathbf{0 . 9 5}$ & $\mathbf{0 . 5}$ & $\mathbf{0 . 8 8}$ & $\mathbf{0 . 4 7}$ & $\mathbf{0 . 8 8}$ & \\
Precipitation & 0.23 & -0.16 & 0.24 & -0.22 & 0.21 & 0.18 \\
Snow height & $\mathbf{0 . 5 3}$ & 0.09 & $\mathbf{0 . 5 8}$ & 0.08 & $\mathbf{0 . 6}$ & $\mathbf{- 0 . 5 1}$ \\
\hline
\end{tabular}


Table 4 Trends of the 1st principal components originating from the different methods

\begin{tabular}{llll}
\hline & $\begin{array}{l}\text { Absolute } \\
\text { trend }\end{array}$ & $\begin{array}{l}\text { Relative } \\
\text { trend }\end{array}$ & $\begin{array}{l}\text { Standard } \\
\text { deviation }\end{array}$ \\
\hline Ground-observed & $\mathbf{- 2 . 9 9}$ & $\mathbf{- 1 . 0 4}$ & 3.37 \\
Slope & $\mathbf{- 5 . 4 0}$ & $\mathbf{- 0 . 9 8}$ & 3.97 \\
Threshold & $\mathbf{- 8 . 0 1}$ & $\mathbf{- 1 . 0 7}$ & 6.12 \\
Slope lowland & $\mathbf{- 5 . 7 4}$ & $\mathbf{- 0 . 9 2}$ & 8.55 \\
Threshold lowland & $\mathbf{- 8 . 6 5}$ & $\mathbf{- 1 . 0 2}$ & 5.98 \\
\hline
\end{tabular}

Absolute trends in days/decade and relative trends in year to year standard deviations/decade $(-)$. Bold numbers indicate statistically significant trends $(p<0.05)$. The spatial variability is indicated by the standard deviation among stations/pixels

trends varied considerably among the different measures (Table 6).

Spatial pattern

The spatial pattern analysis was restricted to the complete threshold SOS data set, since omitting the higher elevation pixels did not reveal noticeable differences from the complete datasets, and the slope method proved to be less suitable for comparison with the ground-observed data. The second phenology pattern of the ground-observed data explained $10 \%$ of total variability. In contrast to the first EOF, no distinct temporal (Fig. 2c), but an interesting regional, pattern was shown (Fig. 3b). Stations in the northern part of the country tended to have more pronounced trends towards earlier onset of spring than stations in the south.

In all satellite-derived phenology datasets, the northsouth pattern was present in both the 1st and 2nd EOF pattern.

The spatial pattern not only represented a north-south effect but also a clear altitude dependence of the trend towards earlier appearance dates. For both the observed as well as for the threshold NDVI, the altitude dependence appeared on the first two EOFs. For the observed phenology, the altitude effect was found mainly on the second order EOF while in the satellite data the first order
Table 6 Trends of the 2nd principal components originating from the different methods

\begin{tabular}{lcc}
\hline & Absolute trend & Relative trend \\
\hline Ground-observed & $-\mathbf{0 . 1}$ & $\mathbf{- 0 . 8 8}$ \\
Slope & -1.84 & -0.47 \\
Threshold & 0.04 & 0.63 \\
Slope lowland. & -2.06 & -0.5 \\
Threshold lowland & 0.32 & 0.21 \\
\hline
\end{tabular}

Absolute trends in days/decade and relative trends in standard deviations/decade $(-)$. Bold numbers indicate statistically significant trends $(p<0.05)$

EOF represented the main altitude effect (Fig. 4). This altitude effect means that the mean trend value for the whole country is rather underestimated for lowland stations and rather overestimated for higher elevation sites. The distribution of the pixels in relation to altitude is somewhat biased by the lowland parts. This is not true for the stations of the ground observation network since the stations are deliberately selected to give an even spatial and altitudinal distribution.

\section{Discussion}

Traditional observational phenology and satellite-derived phenological metrics are very contrasting approaches with different advantages and disadvantages. Ground-observed phenology offers consistent information on development stages of single species, but the observations are unevenly spatially distributed. Satellite phenology provides a general measurement of the photosynthetic activity of the whole vegetation cover and offers full spatial coverage, but is affected by several factors, such as various atmospheric disturbances, solar radiation effects, cloud cover or snow cover duration (Ricotta and Avena 2000; White et al. 2005). Since each pixel generally consists of several land cover types or species, it is important to acknowledge that the phenological events identified are representative of vegetation communities, rather than individual species. The multispecies phenology index used in this study is therefore
Table 5 Correlation of the 2nd principal components originating from the different methods

Bold numbers indicate statistically significant correlations $(p<0.05)$

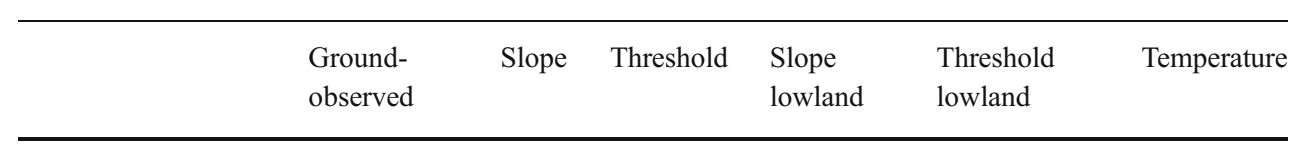

\begin{tabular}{|c|c|c|c|c|c|c|}
\hline Slope & 0.19 & & & & & \\
\hline Threshold & -0.33 & 0.35 & & & & \\
\hline Slope lowland & 0.16 & 0.99 & 0.36 & & & \\
\hline Threshold lowland & 0.02 & 0.6 & 0.46 & 0.58 & & \\
\hline Temperature & 0.79 & 0.08 & -0.27 & 0.04 & -0.06 & \\
\hline Precipitation & 0.37 & -0.03 & -0.58 & -0.04 & -0.56 & 0.25 \\
\hline
\end{tabular}


a

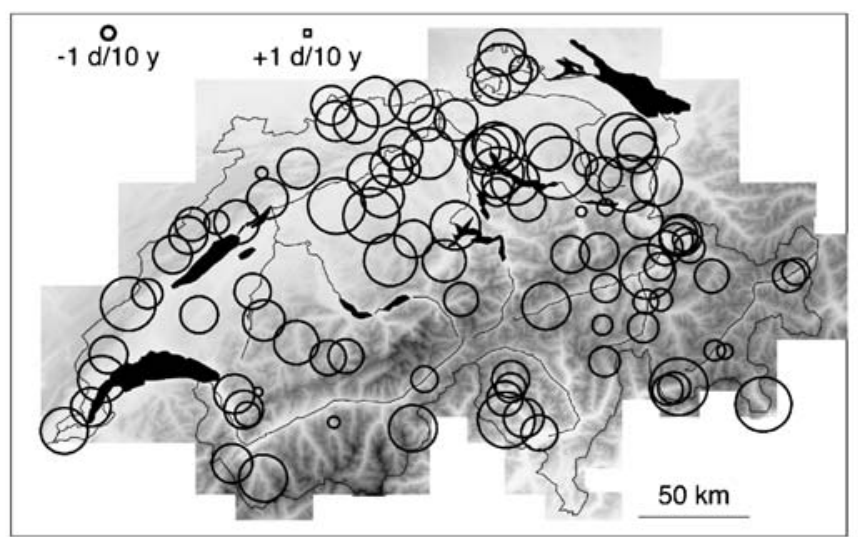

c

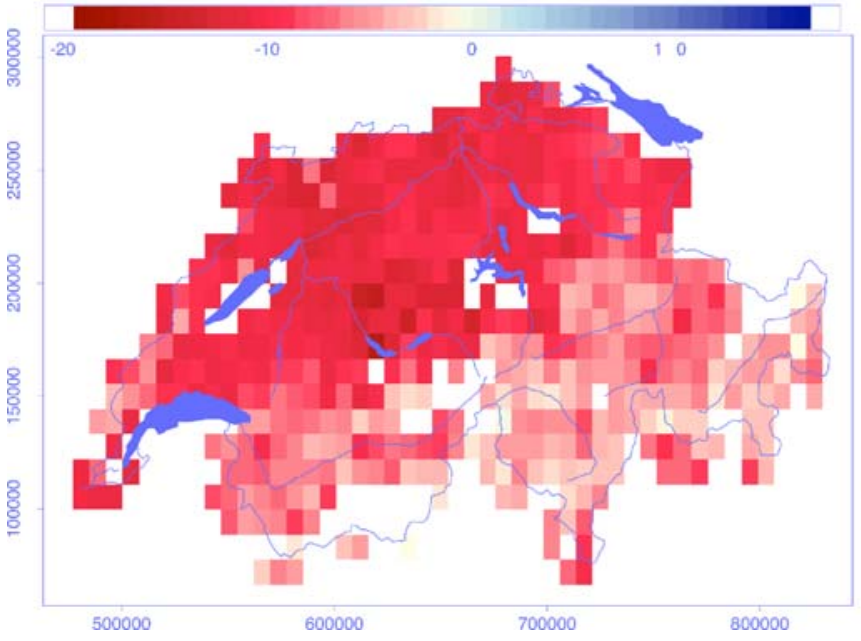

Fig. 3 Spatial pattern of the trends 1982-2001 (EOF pattern scaled to days/decade) of the ground-observed and the threshold NDVI phenology parameters. Axes show Swiss grid (m) coordinates. a, b Circles: negative trend in days/decade; squares: positive trends in days/decade. The grayscale indicates the Swiss topography: light grey: lowlands;

assumed to be a good measurement for a comparison of the two methods (Studer et al. 2005).

Our results demonstrate that there is good correspondence between the traditional observed phenology and the satellite approach to phenology. By means of multivariate statistics, the main trend towards earlier onset of spring and the dominant spatial patterns could be identified with all methods. The agreement on spatial variability shows that satellite-derived phenology can assist in interpreting ground data of low coverage. Nonetheless, the methods also showed considerable differences.

Although the pattern of the trend towards earlier SOS dates was shown by all metrics, the absolute values differed substantially. The satellite-derived trend values were clearly higher (slope: 5.4; threshold: 8 days/decade) than the ground observations (3 days/decade). Myneni et al. (1998) found a very strong trend towards earlier SOS dates for the short period between 1982 and 1990 for the northern b

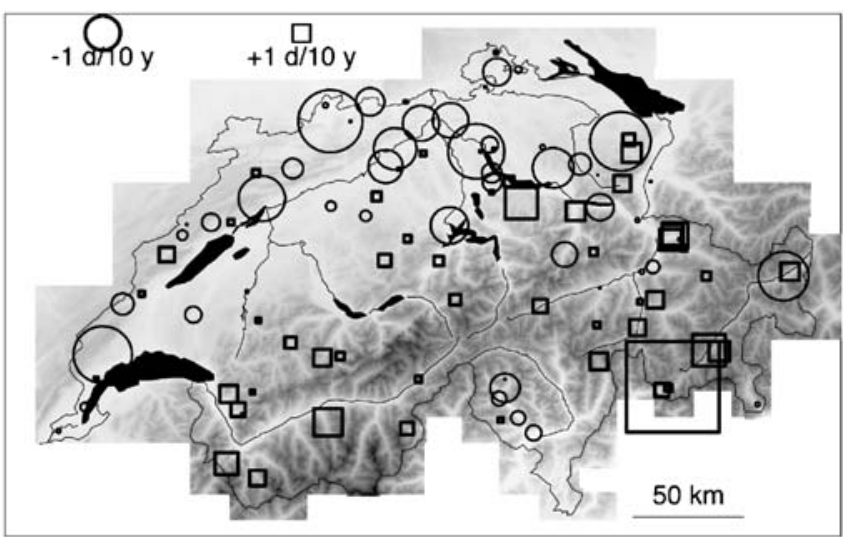

d

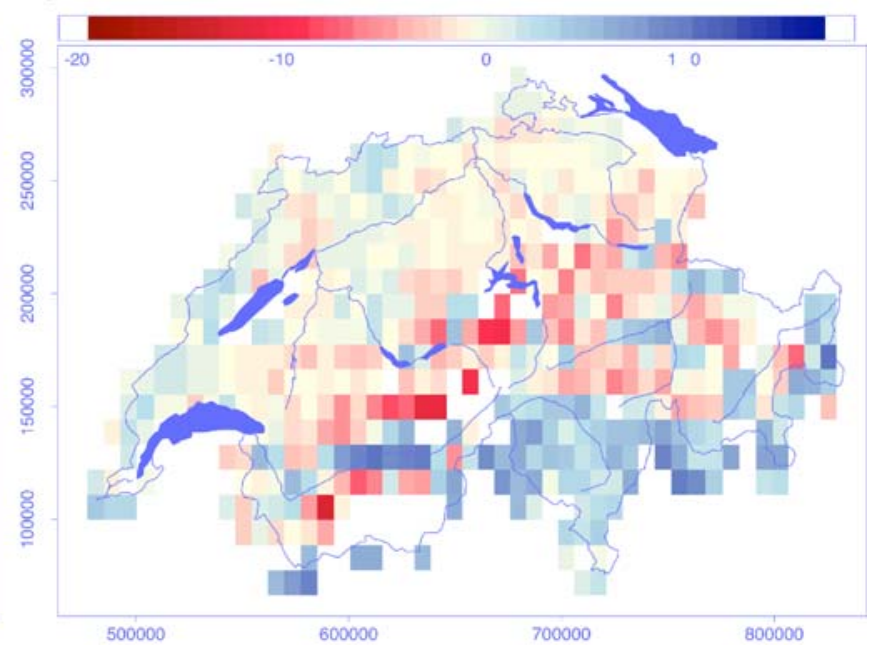

dark grey: higher elevations. a First mode pattern (1st EOF) groundobserved phenology, b second mode pattern (2nd EOF) observed phenology, c, $\mathbf{d}$ Colours indicate trends in days/decade. No analysis was performed for white pixels (water and elevation above 2,000 m). c 1st EOF threshold NDVI, d 2nd EOF threshold NDVI

hemisphere ( 8 days/decade), but trends based on different time periods are difficult to compare, especially if the trend is mainly due to a shift in level (1989-1990), as it is in the current case, than to a continuous change. In another global scale study, (Zhou et al. 2001) found smaller trends by means of satellite phenology for the same time period (3.5 days/decade for Europe and Asia and 4.7 days/decade for northern North America). However, the very consistent relative trends for all measures indicate that the differences in the absolute values are due to the stronger interannual variability within the satellite data. The NDVI derived from AVHRR data is known to be sensitive at low leaf area indices during a green-up (Zhang et al. 2004), implying that the satellite signal possibly measures an earlier state of spring green-up with a stronger interannual variability than the multispecies index based on ground observations. Regarding the descriptive statistics in Table 1 this theory is not confirmed by our data. Further analyses of the raw 
Fig. 4 Mean trend in days/decade explained by the first and the second order EOF of the ground observed and the threshold NDVI pattern in relation to the altitude of the observation station. a Groundobserved 1st order, $R^{2}=0.08$; $p=0.003 ; \mathbf{b}$ ground-observed 2nd order, $R^{2}=0.30 ; p<0.001$; c threshold NDVI 1st order, $\mathrm{R}^{2}=0.42 ; p<0.001 ; \mathbf{d}$ threshold NDVI 2nd order, $R^{2}=0.16$; $p<0.001$
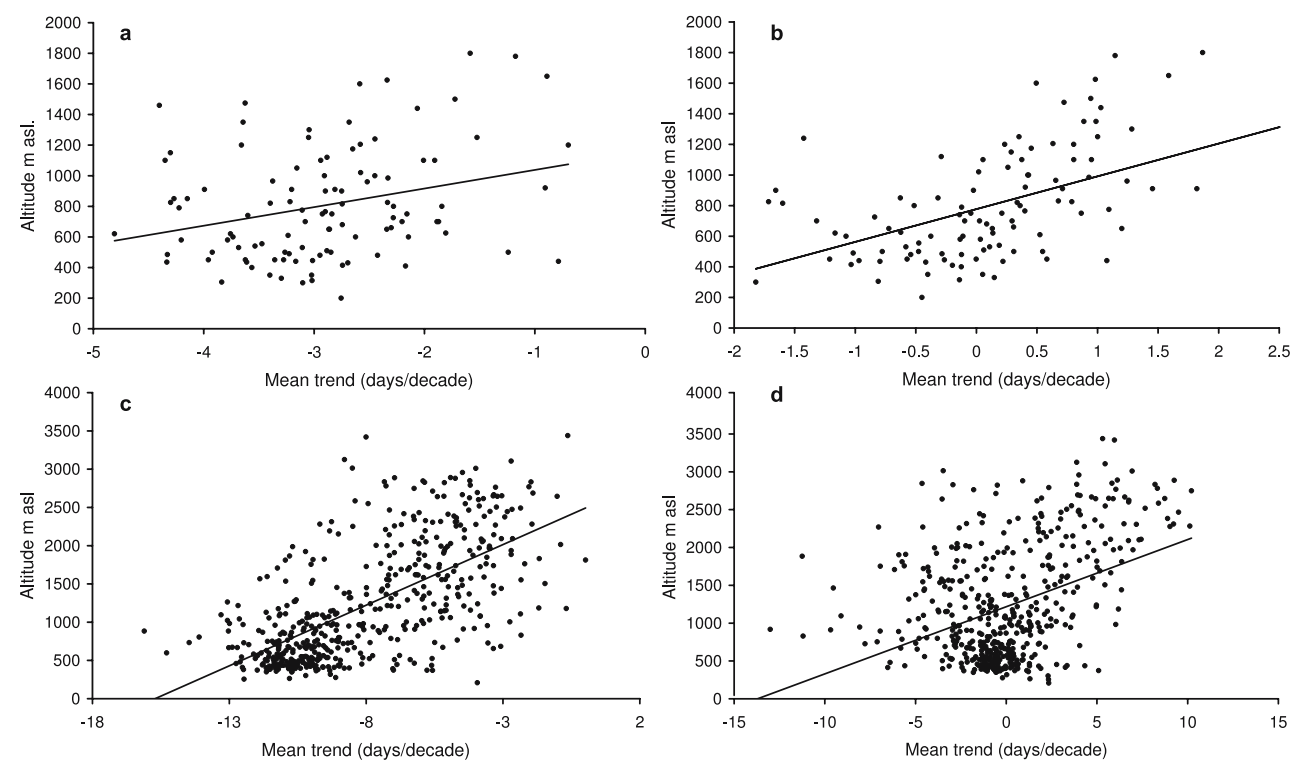

data may show if snow and temperature patterns might also be responsible for the higher interannual variability and the higher trend values in the satellite data.

The slope method to calculate a spring onset parameter on the basis of satellite-derived data is considered to be ecologically more meaningful, because it does not require the use of arbitrarily defined thresholds to identify phenological transition dates (Zhang et al. 2004). Threshold and slope-derived SOS are suggested to be comparable (White et al. 1997), which could not be confirmed in our study. The slope-derived SOS revealed considerable deviations in the temporal development from the threshold- derived SOS. This difference was especially apparent in years with little snow.

Snow cover is known to be a factor of great importance in measuring the onset of photosynthetic activity in spring (Ricotta and Avena 2000; White et al. 2005). The threshold method showed a fairly strong correlation with snow cover, while the slope method did not show any relation with snow cover (Fig. 5; Table 3). The slope method deviates from both the threshold and ground observed SOS dates especially in years with little snow and rather mild temperatures. These conditions favour a very early onset of spring and were most pronounced in winter 1989-1990 (Fig. 5). In
Fig. 5 Time evolution of the leading two principal components of the two satellite NDVI parameters, temperature and snow height

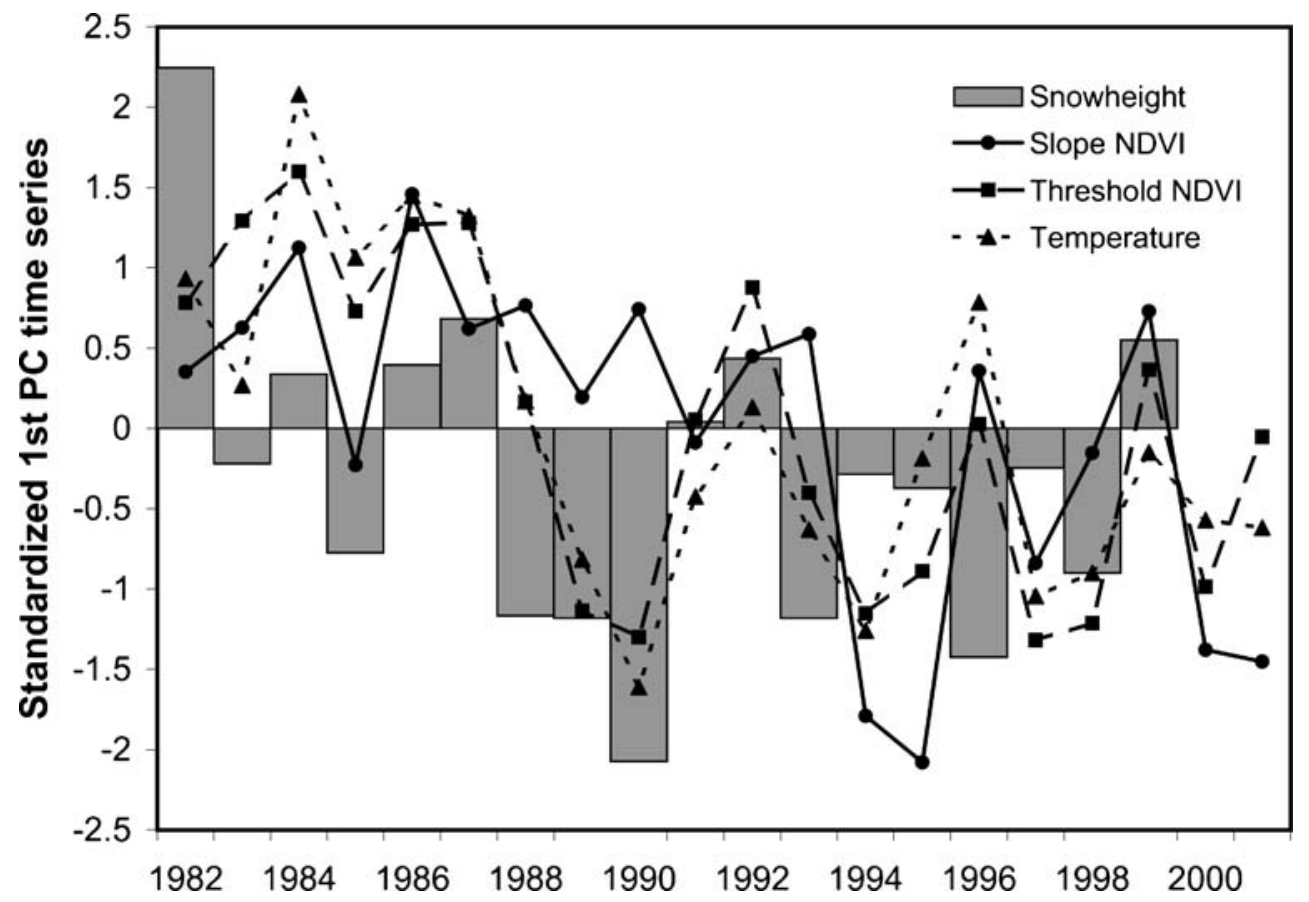


Fig. 1, the two methods are compared for two sample years with very different winter and spring climates. The threshold-derived SOS (dashed vertical lines) uses the same phenological (photosynthetic) state of vegetation for both years: a state which is reached much earlier in 1990 than in 1986. The slope-derived SOS (dash-dotted vertical lines) possibly captures snow-melt in 1986 (high slope, leaves appearing under the melting snow) and leaf-out in 1990. It erroneously predicts an early green-up in 1986. The threshold method proved to be more robust to derive SOS and is less susceptible to the well known snow contamination effects in NDVI time-series.

The satellite-derived SOS estimation not only proved to be able to reflect the temporal development of plant phenology in spring, but also confirmed the spatial pattern found for the ground-observed spring onset index developed by Studer et al. (2005), although the temporal and the spatial pattern were not as clearly separated by the leading EOF patterns. Both methods detected weaker trends at higher altitudes. For temperate ecosystems, spring green-up is mainly driven by temperature. In alpine ecosystems at higher altitudes, other factors such as precipitation (Studer et al. 2005), frost, radiation, snow cover duration, and also plant physiological properties such as dormancy or chilling requirements, may be limiting plant development in spring. But the background of such interrelationships cannot be identified by this study. A starting point for further investigations might be given by Zhang et al. 2004. They found that the number of chill days (days with daily mean temperature $<0^{\circ} \mathrm{C}$ during the period from the start of dormancy to bud burst) is negatively correlated to the accumulated temperature needs (GDD). A general warming leads to less chill days, mainly at high altitudes, and therefore the temperature needs (GDD) increase. This might inhibit an earlier onset of spring at higher altitudes.

\section{Conclusions}

In general, this study showed that satellite-derived phenological SOS estimations are comparable to the integrative multispecies spring index based on phenological ground observations. The absolute trend value is smaller for the ground-observed index ( 3 days/decade) than for the satellite NDVI indices (slope: 5.4; threshold: 8 days/decade). Normalised by their interannual variability all methods are very consistent and show a trend close to 1 /decade.

From the two tested satellite-derived metrics, the threshold method correlated better with the temporal development of the ground-observed phenology index and the temporal pattern of the integrated spring temperature.
Snow anomalies may contribute to the deviation of the slope SOS estimate from the temperature-driven phenological development. The slope method did not reflect several years with a very early spring onset due to very little snow and warm temperatures. The two satellite-derived SOS measures seem to represent different stages of spring onset with a different year-to-year behaviour. The threshold method is therefore better able to represent the temperature dependent temporal pattern of observed phenology.

The good correspondence of the temporal variability and the spatial patterns of ground and satellite phenology demonstrate that they may complement each other. The precise temporal information of ground phenology can be merged with the continuous spatial coverage of satellite phenology. For instance, satellite phenology may be used to explore the complex ecophysiological responses of plant development at higher altitudes, discussed above.

Newer and more sophisticated satellite NDVI datasets (Zhang et al. 2003) from sensors like MODIS (MODerate resolution Imaging Spectroradiometer) with good inflight and pre-calibration technology (Vermote et al. 2002) and accurate snow masks could bring a considerable improvement (Chen et al. 2005). However, such data have only been available since early 2000 .

Acknowledgments This study was carried out in the framework of the National Centre of Competence in Research on climate variability, predictability and climate risks (NCCR Climate) funded by the Swiss National Science Foundation. A part of the study was also funded by the State Secretariat for Education and Research in the framework of the European COST Action 725. The EFAI-NDVI was created under Science Systems and Applications Inc. subcontract 2101-03-002 (NASA contract NAS 5-01070). The support of Prof. Christoph Schär (ETH Institute of Climate and Atmospheric Science) is gratefully acknowledged. The authors thank two anonymous reviewers for constructive comments on the manuscripts. We also thank Dr. S. Scherrer for providing the snow height PC time series data and Dr. Tim Sparks for editing the language.

\section{References}

Ahas R, Jaagus J, Aasa A (2000) The phenological calendar of Estonia and its correlation with mean air temperature. Int $\mathrm{J}$ Biometeorol 44:159-166

Ahas R, Aasa A, Menzel A, Fedotova VG, Scheifinger H (2002) Changes in European spring phenology. Int J Climatol 22:17271738

Beaubien EG, Freeland HJ (2000) Spring phenology trends in Alberta, Canada: links to ocean temperature. Int J Biometeorol 44:53-59

Beaubien EG, Hall-Beyer M (2003) Plant phenology in Western Canada: trends and links to the view from space. Environ Monit Assess 88:419-429

Bounoua L, DeFries G, Collatz GJ, Sellers PJ, Khan H (2002) Effects of land cover conversion on surface climate. Clim Change 52:29-64 
Braun P, Hense A (2004) Combining ground-based and satellite data for calibrating vegetation indices. In: Proceedings SPOT 4/5 Vegetation users Conference, Antwerp, p 5

Bretherton CS, Smith C, Wallace JM (1992) An intercomparison of methods for finding coupled patterns in climate data. J Climate 6:541-560

Cayan DR, Kammerdiener SA, Dettinger MD, Caprio JM, Peterson DH (2001) Changes in the onset of spring in the western united states. Bull Am Meteorol Soc 82:399-415

Chen X, Xu C, Tan Z (2001) An analysis of relationships among plant community phenology and seasonal metrics of Normalized Difference Vegetation Index in the northern part of the monsoon region of China. Int J Biometeorol 45:170-177

Chen X, Hu B, Yu R (2005) Spatial and temporal variation of phenological growing season and climate change impacts in temperate eastern China. Glob Chang Biol 11:1118-1130

Chmielewski FM, Rötzer T (2001) Response of tree phenology to climate change across Europe. Agric For Meteorol 108:101-112

Cihlar J, Manak D, Voisin N (1994) AVHRR bidirectional reflectance effects and compositing. Remote Sens Environ 48:77-88

Defila C, Clot B (2001) Phytophenological trends in Switzerland. Int J Biometeorol 45:203-207

Hannachi A, Jolliffe IT, Stehenson DB, Trendafilov N (2005) In search of simple structures in climate: simplifying EOFs. Int $\mathrm{J}$ Climatol 26:7-28

Hartmann DL (2002) Objective analysis, course notes. University of Washington

Heikinheimo M, Lappalainen H (1997) Dependence of the flower bud burst of some plant taxa in Finland on effective temperature sum: implications for climate warming. Ann Bot Fenn 34:229-243

Holben BN (1986) Characteristics of maximum-value composite images from temporal AVHRR data. Int J Remote Sens 7:1417-1434

James ME, Kalluri SNV (1994) The pathfinder AVHRR land data set an improved coarse resolution data set for terrestrial monitoring. Int J Remote Sens 15:3347-3363

Jollife IT (1986) Principal component analysis. Springer, Berlin Heidelberg New York

Jonsson P, Eklundh L (2002) Seasonality extraction by function fitting to time-series of satellite sensor data. Trans Geosci Remote Sensing 6:1271-1318

Justice CO, Townshend JRG, Holben BN, Tucker CJ (1985) Analysis of the phenology of global vegetation using meteorological satellite data. Int J Remote Sensing 6:1271-1318

Los SO, Collatz GJ, Sellers PJ, Malmstrom CM, Pollack NH, DeFries RS, Bounoua L, Parris MT, Tucker CJ, Dazlich DA (2000) A global 9-yr biophysical land surface dataset from NOAA AVHRR data. J Hydrometeorol 1:183-199

Los SO, Collatz GJ, Bounoua L, Sellers PJ, Tucker CJ (2001) Global interannual variations in sea surface temperature and land surface vegetation, air temperature, and precipitation. J Climate 14:15351549

Menzel A (2000) Trends in phenological phases in Europe between 1951 and 1996. Int J Biometeorol 44:76-81

Menzel A (2003) Plant phenological anomalies in Germany and their relation to air temperature and NAO. Clim Change 57:243-263

Menzel A, Estrella N, Fabian P (2001) Spatial and temporal variability of the phenological seasons in Germany from 1951-1996. Glob Chang Biol 7:657-666

Myneni RB, Keeling CD, Tucker CJ, Asrar G, Nemani RR (1997) Increased plant growth in the northern high latitudes from 1981 to 1991 . Nature $386: 698-702$
Myneni RB, Tucker CJ, Asrar G, Keeling CD (1998) Interannual variations in satellite-sensed vegetation index data from 1981 to 1991. J Geophys Res 103(D6):6145-6160

Parmesan C, Yohe G (2003) A globally coherent fingerprint of climate change impacts across natural systems. Nature 421:37-42

Pielke RA (2001) Influence of the spatial distribution of vegetation and soils on the prediction of cumulus convective rainfall. Rev Geophys 39:151-177

Reed BC, Brown JF, VanderZee D, Loveland TR, Merchant JW, Ohlen DO (1994) Measuring phenological variability from satellite imagery. J Veg Sci 5:703-714

Ricotta C, Avena GC (2000) The remote sensing approach in broadscale phenological studies. Appl Veg Sci 3:117-122

Roetzer T, Wittenzeller M, Haeckel H, Nekovar J (2000) Phenology in central Europe - differences and trends of spring phenophases in urban and rural areas. Int J Biometeorol 44:60-66

Root TL, Price JT, Hall KR, Schneider SH, Rosenzweig C, Pounds JA (2003) Fingerprints of global warming on wild animals and plants. Nature 421:57-60

Scherrer S, Appenzeller C, Laternser M (2004) Trends in Swiss Alpine snow days: the role of local- and large-scale climate variability. Geophys Res Lett 31:(L13215), DOI 10.1029/2004GL020255

Schwartz MD (2003) Introduction. In: Schwartz MD (ed) Phenology: an integrative environmental science. Kluver Academic, Dordrecht, pp 3-7

Schwartz MD, Reiter BE (2000) Changes in North American spring. Int J Climatol 20:929-932

Schwartz MD, Reed BC, White MA (2002) Assessing satellitederived start-of-season (SOS) measures in the conterminous USA. Int J Climatol 22:1793-1805

Sparks TH, Jeffree EP, Jeffree CE (2000) An examination of the relationship between flowering times and temperature at the national scale using long-term phenological records from the UK. Int J Biometeorol 44:82-87

S-PLUS (2000) S-PLUS 6 for Unix. Insightful Corporation, Seattle, WA

Stöckli R, Vidale PL (2004) European plant phenology and climate as seen in a 20 year AVHRR land-surface parameter dataset. Int $\mathbf{J}$ Remote Sensing 25:3303-3330

Studer S, Appenzeller C, Defila C (2005) Inter-annual variability and decadal trends in Alpine spring phenology: a multivariate analysis approach. Clim Change 73:395-414

Tucker CJ, Sellers PJ (1986) Satellite remote-sensing of primary production. Int J Remote Sensing 7:1395-1416

Vermote EF, El Saleous NZ, Justice CO (2002) Atmospheric correction of MODIS data in the visible to middle infrared: first results. Remote Sensing Environ 83:97-111

White MA, Thornton PE, Running SW (1997) A continental phenology model for monitoring vegetation responses to interannual climatic variability. Glob Biogeochem Cycles 2:217-234

White MA, Hoffman F, Hargrove WW (2005) A global framework for monitoring phenologcal responses to climate change. Geophys Res Lett 32(L04705), DOI 10.1029/2004GL021961

Zhang X, Friedl MA, Schaaf CB, Strahler AH, Hodges JCF, Gao F, Reed BC, Huete A (2003) Monitoring vegetation phenology using MODIS. Remote Sensing Environ 84:471-475

Zhang X, Friedl MA, Schaaf CB, Strahler AH (2004) Climate controls on vegetation phenological patterns in northern mid- and high latitudes inferred from MODIS data. Glob Change Biol 10:1133-1145

Zhou L, Tucker CJ, Kaufmann RK, Slayback D, Shabanov NV, Myneni RB (2001) Variations in northern vegetation activity inferred from satellite data of vegetation index during 1981 to 1999. J Geophys Res 106:20069-20083 